\title{
Um traçado analítico da sonoridade cinematográfica na condição de elemento discursivo no dispositivo audiovisual da ficção
}

An analytical layout of the cinematographic sonority in the condition of discursive element in the audio-visual dispositive of the fictional environment

RESUMO: O estudo da trilha sonora cinematográfica aqui apresentado objetivou explorar seus mecanismos de funcionamento na condição de elemento do dispositivo do cinema, de forma que atua diretamente na produção de posições de sujeitos e processos de subjetivação integrantes de produtos fílmicos. Consiste em um trabalho pautado na teoria discursiva de Michel Foucault, sobretudo em seu método de busca de regularidades na dispersão de enunciados, as quais são parte integrante da análise das redes de dispositivos existentes; nesse sentido é que o estudo selecionou determinadas cenas de uma produção cinematográfica para, individualmente, serem analisadas as sequências sonoras ali presentes e sua relação para com os outros elementos, imagéticos e narrativos, resgatados por frames, que constroem o todo da cena. Tal percurso possibilitou a evidência de diferentes sequências sonoras, dispersas no produto fílmico finalizado e que assumem modulações específicas para que se estabeleçam diferentes efeitos de sentido e lugares de sujeito a serem assumidos mediante assimilação e identificação comum a produção artística.

Palavras-chave: Trilha sonora; Dispositivo discursivo; Discurso cinematográfico; Efeitos de saber.

ABSTRACT: The presented study of the cinematographic sound track objectivated the exploration of its mechanisms in the condition of element in the cinema dispositive, in a way that acts directly in the production of subject positions and subjectivation process integrant of filmic products. The research is ruled in the discursive theory from Michel Foucault, mainly in his method of regularities' search in an enunciative dispersion, which one is part of the dispositive network analysis. By these means, the study selected certain scenes of a cinematographic production to, individually, the sonorous sequences being analyzed in their relation to other imagery and narrative elements, rescued by frames, that construct the whole scene. Such course made it possible to see evidences of different sonorous sequences, scattered in the final product and that assume specific modulations to establish different meaning effects and subject places to be assumed upon assimilation and identification with an artistic production.

Keywords: Soundtrack; Discursive device; Cinematographic discourse; Knowledge effects.

\footnotetext{
${ }^{1}$ Graduada em Letras - Português/Inglês e Respectivas Literaturas pela Universidade Estadual de Maringá. Mestranda do Programa de Pós-graduação em Letras (PLE-UEM), Linguística, na área de estudos do texto e do discurso.
} 
Íngrid Livelo. Um traçado analítico da sonoridade cinematográfica na condição de elemento discursivo no dispositivo audiovisual da ficção.

\section{Considerações iniciais}

No âmbito de pesquisas e investigações realizadas com respaldo em teorias discursivas, para além do material originalmente utilizado pelos que conceberam essas últimas, tem-se percebido a abordagem de diferentes materialidades que compõem a comunicação tão cara à vida social e constituição de seus integrantes. De forma a não atribuir um estatuto de "certo", "errado", "possível” e "impossível” para as diversas análises, os estudos discursivos vêm abarcando a própria concepção de que suportes materiais diferentes significam diferentemente no âmbito discursivo, e não por isso são menos válidos de serem estudados em sua complexidade.

É com essa mentalidade que se propôs a pesquisa da qual este artigo é um recorte. Tomando a materialidade cinematográfica, especificamente sua trilha sonora, como objeto a ser estudado, buscou-se delinear alguns aspectos de seu funcionamento a partir dos pressupostos teóricos pautados na teoria do discurso de Michel Foucault. Dessa maneira, o aspecto discursivo da trilha sonora fílmica, que organiza os efeitos de saber (garantidos pelo cinema junto à sonorização), é que tem norteado o estudo ${ }^{2}$ a respeito do encadeamento em rede de dispositivos no discurso do cinema.

Além da possibilidade de ampliação do repertório de análises sobre o componente sonoro do cinema pelo viés discursivo, desenvolveu-se uma reflexão a respeito da trilha sonora de filmes na condição elemento de um dispositivo discursivo, inserido em uma rede pela qual o discurso cinematográfico é vislumbrado. A discussão parte, em instância inicial, da hipótese de que esta rede pode ser considerada um meio de se induzir, deliberadamente, pensamentos daqueles que a assistem a partir da subjetividade construída daqueles que compõem o filme, processo este de construção de um lugar de sujeito que se utiliza da representação visual e tantos outros aspectos em simultaneidade. Logo, para resgatar um questionamento utilizado por Foucault na investigação das relações de saber e poder, qual experiência podemos fazer de nós mesmos, em meio aos discursos que existem?

A fim de sistematizar o referido funcionamento discursivo e investigar os pormenores sonoros, no percurso de pesquisa, foram selecionadas cenas da produção cinematográfica Harry Potter e a Pedra Filosofal (2001), de direção de Chris Columbus, estas acompanhadas por um efeito ou sequência sonora que poderia ser analisada como um conjunto no todo. Aqui

\footnotetext{
${ }^{2}$ Pesquisa que vem sendo desenvolvida desde 2016, inicialmente focalizando o discurso musical no gênero específico do rock dos anos 80 e que, posteriormente, se estendeu à sonoridade cinematográfica enquanto produtora de sentidos e construtora de subjetividades. $\mathrm{O}$ estudo vem sendo feito em acompanhamento com o Grupo de Estudos Foucaultianos da Universidade Estadual de Maringá (GEF-UEM).
} 
Íngrid Livelo. Um traçado analítico da sonoridade cinematográfica na condição de elemento discursivo no dispositivo audiovisual da ficção.

é trazido um recorte do projeto mais amplo que contou com um corpus constituído de 55 cenas, escolhidas mais por seu acompanhamento sonoro do que pela sua significação em relação ao enredo (característica que, para os objetivos de pesquisa, precisou ser suspensa, mas nem por isso é menos significativa). Desse corpus, para o escopo deste artigo, são trazidas quatro cenas, partes da série enunciativa delineada, que contribuíram à identificação de certas regularidades presentes no material todo, identificação esta que mobilizou os conceitos de dispositivo e subjetivação da teoria foucaultiana para que, a partir de análise individual das cenas (tomadas como enunciados), fosse possível chegar ao efeito da trilha sonora em simultaneidade com a imagem.

São apresentados, inicialmente, alguns dos elementos do aporte teórico discursivo para, em seguida, ser possível delinear considerações sobre o dispositivo audiovisual e posições de subjetivação adjacentes. Então, é apresentada a natureza da produção fílmica investigada juntamente a explicações de sua escolha para, enfim, se trazer as regularidades selecionadas para este texto com o auxílio dos frames de cena. Por tal percurso, elegendo a trilha sonora como um dos dispositivos atuantes no discurso fílmico e estabelecendo algumas regularidades geradas dentro da série enunciativa, entende-se o cinema como um domínio de leis que participam de um contexto amplo da atividade e da natureza humana, além de se explanar um possível trajeto oriundo das teorias discursivas que permanecem tangendo diferentes materialidades.

\section{Aspectos teóricos sobre o dispositivo e o caminho discursivo foucaultiano}

A trajetória de Foucault para a estipulação de uma forma de descrição dos enunciados e, logo, dos discursos nos quais se inserem perpassa por diversas formulações que, a princípio, são advindas do que até então se define como método arqueológico. Em vista de investigar uma história geral em detrimento de uma global, o filósofo questiona que tipos de séries instaurar, que interrupções e formas de ruptura aparecem nas recorrentes distribuições que se fazem nas sociedades, enfim, "em que conjuntos distintos certos elementos podem figurar simultaneamente; em resumo, não somente que séries, mas que 'séries de séries' [...] é possível constituir" (FOUCAULT, 2008, p. 11).

Da extensa e rica discussão arqueológica do saber é que emergem tantos outros caros conceitos a um estudo discursivo de cunho foucaultiano, e a premissa comum é a descontinuidade, a qual vai para muito além de falhas na história genealógica. Tendo em vista 
essa história descontínua e tudo que a ela se implica, pode-se compreender o enunciado como singular, com suas próprias condições de existência e, assim, encarar as produções de diversas materialidades como acontecimentos. Sobre a conceituação de acontecimento, Navarro (2018) explica, conforme Foucault, que:

acontecimento não é uma coisa, um objeto consistente, não é substância, acidente, qualidade ou processo. Não é também da ordem dos corpos, mas nem por isso deixa de ter uma materialidade, já que é justamente na materialidade que ele tem efeito e lugar. $\mathrm{O}$ acontecimento não apresenta uma unidade material, porque se produz numa dispersão material. Ele é feito de cesuras que dispersam o sujeito em uma pluralidade de posições e de funções (NAVARRO, 2018, p. 271).

Como já previsto no excerto, a questão do sujeito disperso também vai tanger as noções de acontecimento e história, pois esta, sendo descontínua, receberá um sujeito também descentrado a ser incluído em seus domínios. Considerando essa conceituação de sujeito e as diversas enunciações - manifestadas em dispersão, específicas de determinada prática discursiva -, o caminho proposto por Foucault é o de buscar "um campo de regularidade para diversas posições de subjetividade [...] um conjunto em que podem ser determinadas a dispersão do sujeito e sua descontinuidade em relação a si mesmo" (FOUCAULT, 2008, p. 61).

Por esse viés é que se dão os mais diversos estudos discursivos, e é a partir dele que o próprio filósofo avança em direção ao que é chamado de "uma genealogia cujo motor é a descontinuidade" (NAVARRO, 2018, p. 269), fase na qual, sem perder de vista a conceituação de sujeito tecido nos enunciados, a teoria foucaultiana se envereda para o estudo da relação dos saberes com o poder, especialmente em analisar este último por meio de práticas discursivas e não discursivas e sua manifestação em diferentes formas de objetivação e subjetivação:

Além da ideia de que o homem é datável, já que sua aparição se dá num determinado momento, quando se torna objeto do saber, ele passa a ser também alvo de um poder, não centralizado em aparelhos ideológicos, mas disperso em práticas discursivas, tais como: a psiquiatria, a medicina, economia, ou a mídia, seja ela impressa ou eletrônica [...]. Nessa visada teórica, esse tipo de sujeito constituinte não encontra condições de existência, visto que o objetivo é analisar a constituição do sujeito na trama histórica da qual participa, investigar os procedimentos discursivos dos quais se valem as práticas discursivas para instituir e legitimar processos de subjetivação (NAVARRO, 2018, p. 272). 
Íngrid Livelo. Um traçado analítico da sonoridade cinematográfica na condição de elemento discursivo no dispositivo audiovisual da ficção.

Pela amplitude de subjetivações possíveis em tantos momentos/acontecimentos do discurso na atualidade, o cunho de prática "não discursiva" possibilita a abrangência de materialidades outrora tidas como suportes, não de menos valor, mas que nesse tratamento assumem um estatuto de existência material do enunciado, do qual advém as posições subjetivas que podem, então, ser assumidas por múltiplos sujeitos. O discurso, dessa forma, não se restringe a signos justapostos, mas se configura como uma prática, com determinações históricas pelas quais se vislumbram efeitos de saber-poder.

A fim de tomar o cinema como imbuído de características materiais (bem destacado, conforme a teoria discursiva) que permitem encará-lo como uma prática na qual sujeitos enunciam e são enunciados conforme as condições históricas em que se situam ou que representam na duração da produção audiovisual, toma-se aqui a seguinte definição: “A materialidade do enunciado remete, portanto, às condições de possibilidade - um mesmo espaço de distribuição, a mesma repartição de singularidades, a mesma ordem de lugares e locais e a mesma relação com o meio instituído - que o tornam repetível" (NAVARRO, 2018, p. 277). Por conseguinte, tendo em mente essas condições de possibilidade, é possível direcionar o olhar teórico a um conceito central do presente estudo, o dispositivo, conforme conceituado por Foucault (2013) como um conjunto heterogêneo, formado por discursos, instituições, estruturas, organizações arquitetônicas, leis, enunciados científicos, o dito e o não dito.

Aqui também é tomado o dispositivo conforme a leitura de Agamben (2005, p. 13):

Qualquer coisa que tenha de algum modo a capacidade de capturar, orientar, determinar, interceptar, modelar, controlar e assegurar os gestos, as condutas, as opiniões e os discursos dos seres viventes. Não somente, portanto, as prisões, os manicômios, o panóptico, as escolas, as confissões, as fábricas, as disciplinas [...] mas também a caneta, a escritura, a literatura, a filosofia, a agricultura, o cigarro, a navegação, os computadores, os telefones celulares e - porque não - a linguagem mesma (AGAMBEN, 2005, p. 13).

Considerando essas explanações do dispositivo, ao se tomar o cinema e sua multimodalidade (imagem e som), é possível identificar funcionamentos específicos que guardam relação com a subjetividade presente nesse meio artístico. Como destacam Carvalho e Sargentini (2017), em leitura do dispositivo da teoria foucaultiana, este teria também a capacidade de agir na produção de subjetivações e de sustentar estratégias de tipos de saber, bem como ser sustentado por esses tipos. É dessas relações imbricadas que se vislumbra a rede constituinte do dispositivo, e é esse exercício que se pretendeu realizar com a 
Íngrid Livelo. Um traçado analítico da sonoridade cinematográfica na condição de elemento discursivo no dispositivo audiovisual da ficção.

materialidade cinematográfica, de forma que puderam ser identificadas relações de saber e poder no microcosmo que é representado no filme.

Nesse movimento analítico se afirma outro aspecto do dispositivo, que diz respeito às linhas de visibilidade e de enunciação, uma vez que "os dispositivos são máquinas de fazer ver [...] [e] fazem falar, conforme uma determinada teoria, estilo literário, um saber científico etc.” (NAVARRO, 2018, p. 288). Tal aspecto dá espaço para se falar em dispositivo audiovisual, considerando-se que uma produção cinematográfica atua, direta ou indiretamente, nos processos de subjetivação, até mesmo os compondo por si própria, para que seja possível aos sujeitos assumirem posições e passarem por identificações.

\section{O dispositivo audiovisual em meio às produções discursivas}

Ao tratar da natureza das referidas relações de saber-poder, bem como do que seria o dispositivo que nelas age e as molda, Foucault (1988) encara a experiência como imprescindível a esse estudo, no sentido de que é pela experiência do sujeito com a sociedade e consigo mesmo que se vislumbra o modo como a sociedade se discursiviza. A experiência para Foucault articula os campos de saber, o poder e as formas de subjetividades, e por isso é que se utiliza dela para analisar a sexualidade (mais detidamente) como dispositivo da maneira que o fez em parte de suas obras.

Essa abordagem da experiência com suas articulações se constitui como uma grade de leitura com a qual se estabelece caminhos para entendimento de determinada instância de saber-poder social. Não se esgotando as possibilidades de grades que permitem a entrada discursiva a um material fílmico, os saberes e as subjetividades inerentes à trilha sonora são os meios pelos quais se busca a análise do dispositivo audiovisual, e essa grade possui determinada composição e características.

Para que as posições de subjetivação se construam diante não só do material cinematográfico aqui tomado, mas também para outros de natureza semelhante, o dispositivo audiovisual atua de forma essencial à produção de subjetivações aliada ao meio multimodal. A trilha sonora, nesse sentido, possui contornos que permitem seu entendimento como integrante da rede de dispositivos do cinema, que também estabelece saberes e poderes; uma vez que aqui se toma o conjunto cena visual mais trilha sonora, executada concomitantemente à cena, para compor a grade de leitura das posições de sujeito daí resultantes, alguns conceitos 
Íngrid Livelo. Um traçado analítico da sonoridade cinematográfica na condição de elemento discursivo no dispositivo audiovisual da ficção.

semióticos foram emprestados a seguir para entendimento teórico desse meio, sendo, inclusive, muitos deles bastante próximos à teoria discursiva.

De acordo com Andrew (2002, p. 190), “o significado [de um produto fílmico] não existe simplesmente, precisa ser criado", e o olhar semiótico conceitua os chamados canais de informação para que tal criação seja feita, a saber: imagens fotográficas em movimento; traços gráficos que incluem todo o material escrito que é lido em off; discurso gravado; música gravada e barulho ou efeitos sonoros gravados. Especialmente os três últimos canais corroboram o que o mesmo autor explica como recusa de um status privilegiado da imagem, pois "a maioria dos filmes foi feita como se as imagens fossem predominantes; no entanto é possível conceber filmes cujo equilíbrio de materiais favoreça o diálogo ou até a música" (ANDREW, 2002, p. 175). Vale acrescentar que o referido equilíbrio ou a falta dele pode, inclusive, suscitar diferentes efeitos de sentido, o que não invalida este ou aquele produto audiovisual.

Desde que a música é parte da poética do cinema, constituindo sua linguagem heterogênea e sendo considerada mesmo a primeira sonoridade cinematográfica (anterior à gravação de falas, por exemplo), seu trabalho junto à imagem oferece peculiaridades a respeito de seus efeitos emergentes. Conforme Alves (2012), no cinema, imagens e sons não existem por si sós, de forma que o movimento é o de "despertar no espectador um 'ponto de escuta' e também aumentar a complexidade de seu "ponto de vista"' (p. 95). A trilha sonora explora essa complexidade na medida em que pode participar diretamente da emoção da cena, dando-lhe o tom pretendido (um exemplo é $O$ nascimento de uma Nação, dirigido por David Griffith em 1915, que utilizou a composição original como elemento narrativo) ou, ainda, sendo-lhe contrária e, até mesmo, irônica, não deixando de criar sentidos por estar nesse movimento com a cena e o andamento do enredo.

Tais características contemplam a condição do audiovisual como dispositivo, inclusive conduzindo à formação de uma memória. Sob a perspectiva discursiva, Milanez, Barros-Cairo e Braz (2017, p. 226) consideram o audiovisual como "a teia de dispositivos discursivos sob a forma de filmes e vídeos", na qual existe uma memória histórica de como as produções de imagem circulam no corpo social dos sujeitos. Também retomando a visão foucaultiana de um domínio de memória, tem-se que o enunciado como acontecimento nunca se esgota inteiramente e "abre para si mesmo uma existência remanescente no campo de uma memória [...] é único como todo acontecimento, mas está aberto à repetição, à transformação, à reativação" (FOUCAULT, 2008, p. 32). Assim, propriamente do funcionamento de um 
dispositivo, a materialidade audiovisual faz a manutenção de certos domínios memoriais, a fim de fazer esquecer enunciados em detrimento de outros que podem ser ditos.

O modo de enunciação não deixa de ser, também, pertinente e influente quanto ao efeito que lhe sucede, sendo mesmo uma estratégia no âmbito cinematográfico para a criação de um saber sobre o sujeito. Dentre seus aspectos, vale destacar as posições de câmera (fixa, em movimento, com zoom ou em travelling, por exemplo) e modos de enquadramento no que tange à imagem; no que concerne à parte sonora, tem-se diferentes volumes e andamentos diferentes (compassado, staccato, legato, entre outros) de uma mesma sequência de notas, ou até mesmo composições advindas de outras origens que não o cinema, por exemplo canções populares ou de bandas famosas, que são inseridas em um filme para produzirem determinado significado. Cada combinação de um elemento diferente, por conseguinte, provoca modificações no que estava sendo produzido.

Ainda a respeito das técnicas cinematográficas, em especial as sonoras, Carrasco (2010) delimita dois níveis identificáveis na articulação de som e imagem:

1) Dramático/narrativo, utilizado para narrativas de definição de personagens; também tem o poder de se associar ao diálogo para estabelecer seu estado emocional e possíveis caminhos pelos quais seguir.

2) No que se refere ao movimento visual e ao movimento sonoro, por exemplo, uma montagem de ações rápidas, com cortes sucessivos e fragmentados, geralmente é acompanhada de um som de andamento acelerado.

Além desses, também se encontra em Carrasco (2010) uma sucinta definição da técnica de leitmotiv, ou "motivo condutor", que caracteriza um tema musical a determinado elemento que será usado recorrentemente no filme:

um tema de personagem pode ser transformado para revelar o estado emocional dessa personagem em cada um dos momentos do filme. Leitmotivs famosos permanecem como ícones do filme nas mentes dos espectadores e, quando ouvidos, remetem imediatamente ao filme. Alguns exemplos famosos são o "Tema de Tara", de Max Steiner, em E o vento levou; a "Raider's March", tema de Indiana Jones de John Williams; ou o famoso tema de Tubarão, também de Williams, que literalmente substitui o tubarão, que poucas vezes é visto no filme (CARRASCO, 2010, p. 0-0, grifo do autor).

Tal motivo condutor aplicado à trilha sonora contribui à construção da memória não somente dentro do microcosmo do filme, mas também ao que se encontra exterior à tela, ao redor dos espectadores, os quais também se utilizam desses meios delimitadores para se 
guiarem na compreensão, identificação, enfim, em sua posição subjetivada à produção audiovisual diante da qual se encontra.

Não necessariamente presentes em todas as produções do cinema de determinada época, ou mesmo em sua maioria, essas técnicas possibilitam compreender os meios pelos quais se pode fazer a manutenção de películas e torná-las, não inocentemente, produtoras de

sentidos e identidades. É por tal conjuntura e se explorando as referidas técnicas que se alcança a profundidade realista do filme, tão pertinente ao se propor o projeto dessa natureza, não importando o gênero narrativo, pois mesmo as ficções se utilizam dessa profundidade para tornar crível aquilo que representam e contribuir, assim, para a identificação e/ou subjetivação dos sujeitos envolvidos.

Enfim, para se propor o seguimento por um dos muitos caminhos analíticos possíveis com essa materialidade heterogênea, faz-se necessário retomar o pressuposto de Foucault (2008) de que certo domínio do discurso pode ser delineado se constituído por um "conjunto de todos os enunciados efetivos (quer tenham sido falados ou escritos), em sua dispersão de acontecimentos e na instância própria de cada um” (p. 29-30) e, a partir dessa dispersão, puder ser identificada uma regularidade. Essa regularidade dispersa é o que permitiu, até então, a investigação da trilha sonora por um viés discursivo de forma que seja considerada componente do dispositivo audiovisual no meio cinematográfico.

\section{Os efeitos de saber da sonoridade de um cinema "bruxo"}

Faz-se pertinente aqui uma breve reflexão acerca do produto fílmico fictício, uma vez que a série enunciativa da qual a análise é exposta adiante advém do meio cinematográfico tido como ficcional. Tal característica desse meio possui um funcionamento próprio discursivamente e no âmbito de suas condições de produção, pois um dos objetivos primeiros é que certa realidade seja apresentada de forma crível. Vernet (2012) aborda o filme de ficção como portador de uma dupla representação: irreal por seu enredo/história e irreal pelo modo como representa (imagens de objetos, atores caracterizados para determinada história etc.). $\mathrm{Na}$ irrealidade do enredo, especificamente, identifica-se a capacidade do cinema de ausentar, do tempo e do espaço, aquilo que mostra ao espectador, já que a cena fora registrada e já se passou inscrita em um lugar que não a tela de projeção; assim, Vernet completa que o espectador suspende outras atividades durante a projeção do filme, em uma espécie de devaneio corroborado pelo ambiente de projeção, pelas cenas e a sequência na qual se 
apresentam, pela trilha sonora que acompanha cada uma delas e que pode ditar impressões ou interpretações.

Por esses meios, são "várias formas (modos de representação, conteúdo, procedimentos de exposição) que qualquer filme, de qualquer gênero, pode pertencer à ficção" (VERNET, 2012, p. 102). Nos trabalhos de ficção produzidos frequentemente se procura que ele soe "naturalmente", se desenvolva de forma fluida, característica que, em termos discursivos, poderia se dizer que propicia a criação de um espaço de sujeito para que o espectador ali se coloque, assumindo uma posição subjetiva semelhante à apresentada. A fim dessa fluidez, tais filmes tendem "a escolher como tema as épocas históricas e os pontos de atualidade a respeito dos quais já existe um 'discurso comum"” (VERNET, 2012, p. 106), submetendo-se à realidade enquanto tenta tornar sua fábula verossímil.

Essa característica pontuada anteriormente pode ser entendida como uma regularidade dos produtos fílmicos de caráter fictício, bem como a margem de ação destinada aos personagens, de forma que se constituam no interior da película. Uma vez que qualquer dos efeitos produzidos tem dependências nessa construção, os aspectos sonoros podem se unir aos personagens e possibilitarem a emergência de diversas implicações, como personagens que têm uma "música tema" a qual passa por variações no decorrer da produção, mas mantém a mesma sequência sonora e, assim, ajuda na caracterização daquele ou daquilo que representa/acompanha.

Somando a dramaticidade - a qual faz com que certa sequência de sons possa indicar estados emocionais dos personagens - às técnicas apresentadas e tecnologias disponíveis para a criação de efeitos sonoros, não é arriscado dizer que a trilha sonora cinematográfica abrange tantos pormenores e detalhes de (re)produção que ultrapassa o conceito de "uma música de fundo" do cinema mudo antigo. Compreendida nos moldes discursivos, ela se apresenta permeada de relações de sentido observáveis pelos dispositivos que se entremeiam ao cinema.

Antes de dirigir a atenção aos movimentos analíticos traçados nessa materialidade fílmica a partir da teoria discursiva foucaultiana, convém explanar algumas das condições de produção empíricas da produção em questão.

O filme Harry Potter e a Pedra Filosofal (2001) é um longa-metragem que obteve ampla aceitação em meio a um público de faixa etária variada, ainda que se constitua como adaptação para o cinema do livro, de mesmo título, caracterizado como literatura infantojuvenil e lançado alguns anos antes de sua produção fílmica. Sendo essencialmente uma história aventureira e de fantasia, todos os outros seis livros posteriores foram transpostos ao mundo cinematográfico, para narrar audiovisualmente a jornada do jovem bruxo, cujo nome 
dá título ao filme, enquanto estudante da escola de magia da saga, conhecendo o mundo mágico e enfrentando o principal vilão que está em busca de poder e controle na/da sociedade bruxa. A composição da trilha sonora foi de responsabilidade, primeiramente, de John Williams, renomado pela produção musical de clássicos do cinema e que estabeleceu um dos principais leitmotiv da saga, intitulado Hedwig's Theme, o qual acompanhou os filmes subsequentes (com direção sonora de Patrick Doyle, Nicholas Hooper e Alexandre Desplat) recebendo, a cada um, algum detalhe diferenciado, fosse nos instrumentos ou no andamento das notas.

Diante da atuação dessa produção, que movimentou diferentes públicos e instâncias relacionadas à cultura audiovisual do cinema, vale aqui a menção a um dos pensamentos primordiais da teoria discursiva que dá respaldo a este estudo:

O livro faz uso de documentos verdadeiros, mas de maneira que, através deles, seja possível efetuar não somente uma constatação de verdade, mas também uma experiência que autoriza uma alteração, uma transformação da relação que temos conosco mesmos e com o mundo. [...] A experiência pela qual chegamos a alcançar, de maneira inteligível, certos mecanismos (por exemplo, o aprisionamento, a penalização etc.) e o modo como chegamos a nos distanciarmos deles, percebendo-os de outra forma, só devem fazer uma única e mesma coisa. [...] essa experiência, enfim deve poder estar ligada, até certo ponto, a uma prática coletiva, a uma forma de pensar (FOUCAULT, 2010, p. 294-295, grifos meus).

Com tal cenário da uma trilha sonora que, certamente, possibilitou processos de identificação e subjetivação de muitos espectadores, infanto-juvenis ou não, em concomitância ao universo bruxo criado, o processo de análise desse componente e das cenas selecionadas que se segue resgatou relances de seu funcionamento discursivo a partir da rede de dispositivos que se relacionam à trilha sonora e às regularidades daí geradas.

\section{Sequências musicais que se dispersam e se tornam efeitos}

Conforme mencionado no decorrer da descrição de características do dispositivo audiovisual, uma das técnicas recorrentes aos filmes, sejam partes de sagas fictícias ou não, é a do leitmotiv que estabelece uma música tema a um personagem ou outro elemento do enredo. Considerando-se que a produção aqui analisada gira em torno da história de um sujeito em específico, fica parcialmente dada a existência de uma música tema que permeia 
esse e os demais filmes, em momentos diferentes e com emoções/sentidos diferentes, mas que sempre se faz presente de uma forma ou outra.

Para se avançar a outras peculiaridades da trilha sonora além da música tema, mais detidamente aqui serão analisadas outras duas formas de sequências musicais que delineiam efeitos de sentido outros para com a imagem cinematográfica.

\section{Sincronia do imagético e da sonoridade - primeira sequência}

Esta regularidade pode ser denominada como uma das cadeias de variáveis que fazem ver e fazem falar, pois, conforme os canais de informação semióticos, a música gravada aqui vem de forma a corroborar ao efeito do âmbito imagético. Tal encontro de canais contribui fortemente no estabelecimento da relação subjetiva de identificação do espectador, ao nível de desejos, angústias, similaridades e diferenciações; uma vez que filmes fictícios possuem códigos de interpretação (a fim de que, mesmo fantasiosa, sua realidade se torne "possível" em presença do filme a quem o produz e, posteriormente, a quem o assiste), estes auxiliam na condução do olhar, de forma a guiá-lo pela narrativa e, consequentemente, se utilizam dos efeitos sonoros possíveis a determinada cena.

A soma da trilha sonora em uma mesma direção à do sentido da imagem e da narrativa, por esses meios, pode ser considerada uma configuração coletiva que estabelece padrões, por exemplo, recorrentes a cenas de ação, de terror, de comédia, entre outros facilmente identificáveis pela simples reprodução de determinadas notas musicais. Nesse sentido interpretativo é que essas sequências sonoras se constituem como subcódigos que possuem um campo associativo: as formulações em cena e o domínio musical ditam as regras de aparição de tais enunciados e tais significados que se extraem do que está sendo reproduzido em tela. Segue uma ocorrência dessa sequência: 
Imagem 1 - Frame 1 da chegada de Hagrid

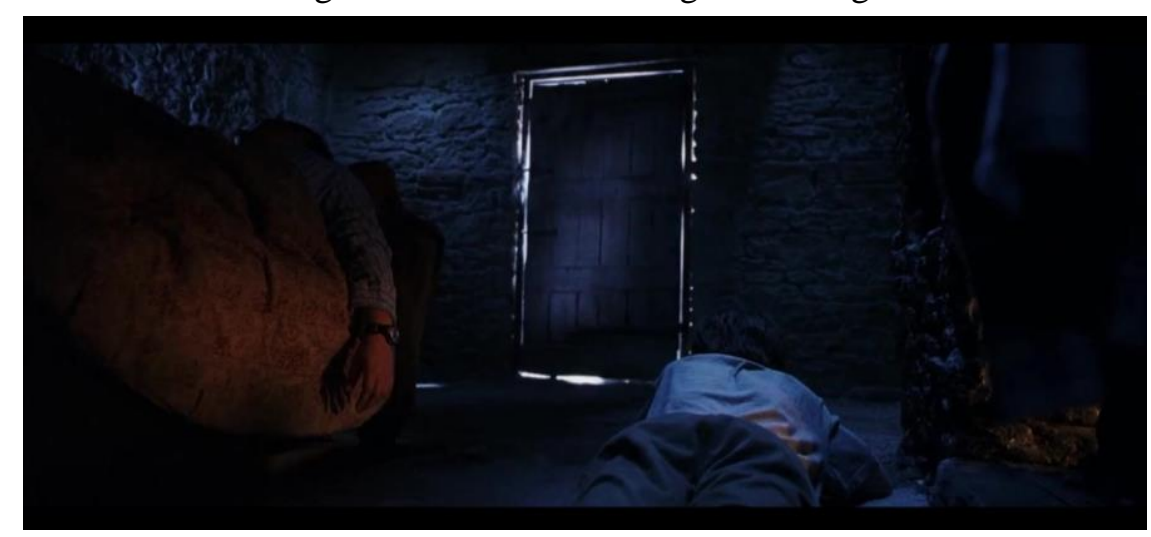

Fonte: Harry Potter e a Pedra filosofal (12'55'” à 13'22”') .

Imagem 2 - Frame 2 da chegada de Hagrid

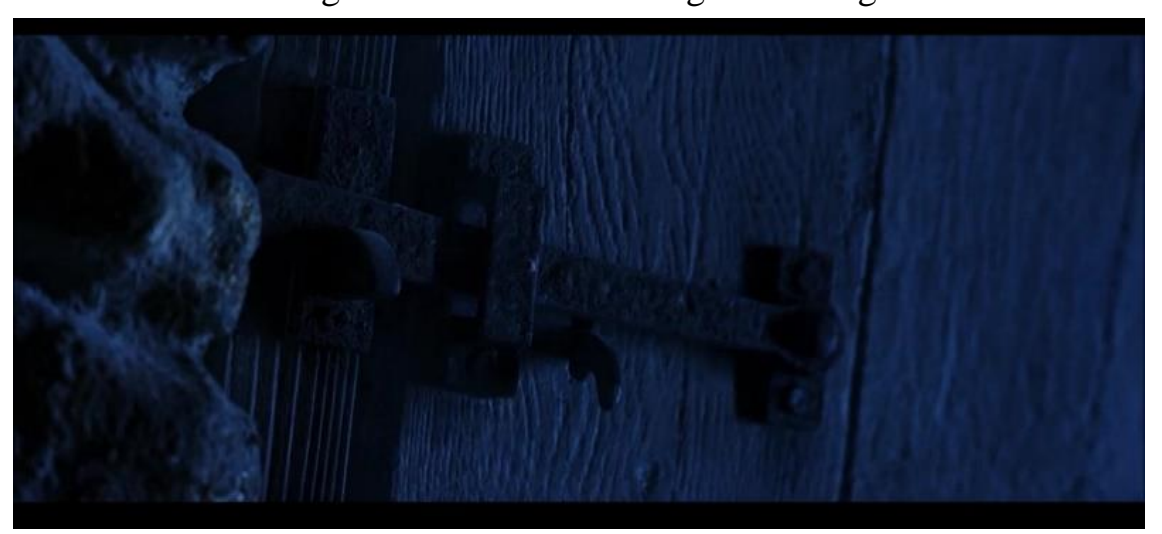

Fonte: Harry Potter e a Pedra filosofal (12'55'” à 13'22'').

A montagem da cena alterna diferentes focos, iniciando com a grande porta e um acompanhamento sonoro em baixo volume, inclusive mostrando o protagonista na parte inferior, desenhando as palavras "happy birthday" de forma a situar o momento na cronologia narrativa. A aparente ordem é perturbada com um estrondo visual e sonoro vindo da porta, com alguém tentando abri-la, e a partir daí os cortes sucessivos focam ora nos personagens, ora na fechadura in close, prestes a se romper; o acompanhamento musical, então, possui um volume elevado, o qual vai crescendo aos poucos até que a porta vem abaixo e surge o personagem que, em primeiro plano, se apresenta assustador.

\footnotetext{
${ }^{3}$ Referência completa na seção correspondente, ao final do documento.
} 
Imagem 3 - Frame 3 da chegada de Hagrid

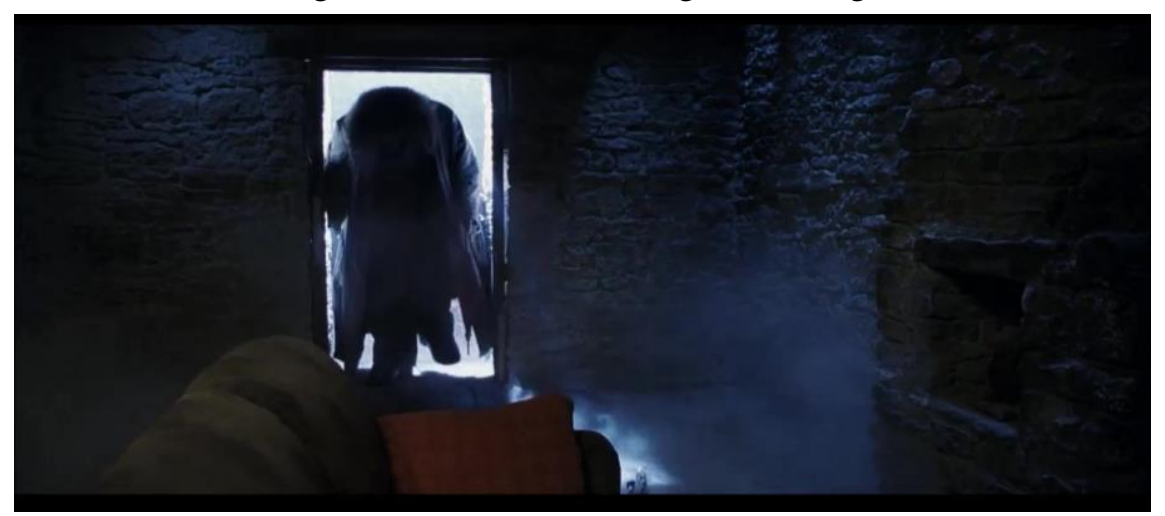

Fonte: Harry Potter e a Pedra filosofal (12'55'’ à 13'22'").

O efeito de algo que amedronta logo em seguida é desconstruído pelo diálogo do personagem recém-chegado, mas até então o que prevalece sonoramente é o suspense acerca do desconhecido que irrompe.

Outro exemplo desse funcionamento está na apresentação de um elemento comum a histórias de bruxaria e que, no filme em questão, também é resgatado: os fantasmas. Em momentos posteriores da história, alguns dos personagens fantasmas exercem papel importante como determinantes narrativos; na cena da qual se extraiu o frame seguinte, é feita sua primeira aparição no filme com alguns fragmentos de diálogos que já mostram suas personalidades e o modo como se relacionam com os vivos.

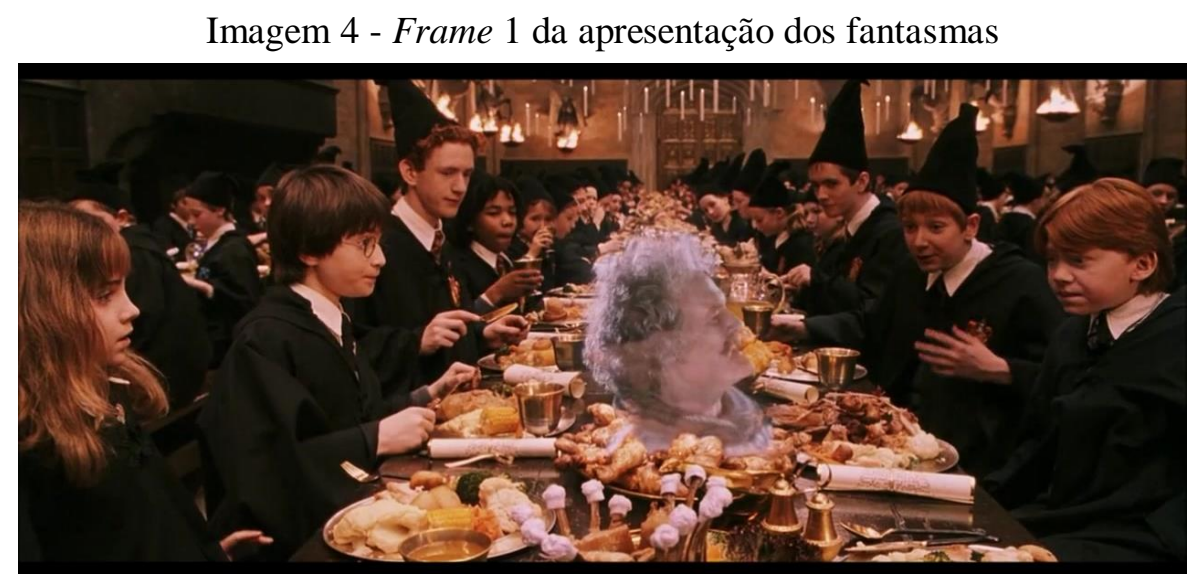

Fonte: Harry Potter e a Pedra filosofal (47'07', à 47'32' '). 
Imagem 5 - Frame 2 da apresentação dos fantasmas

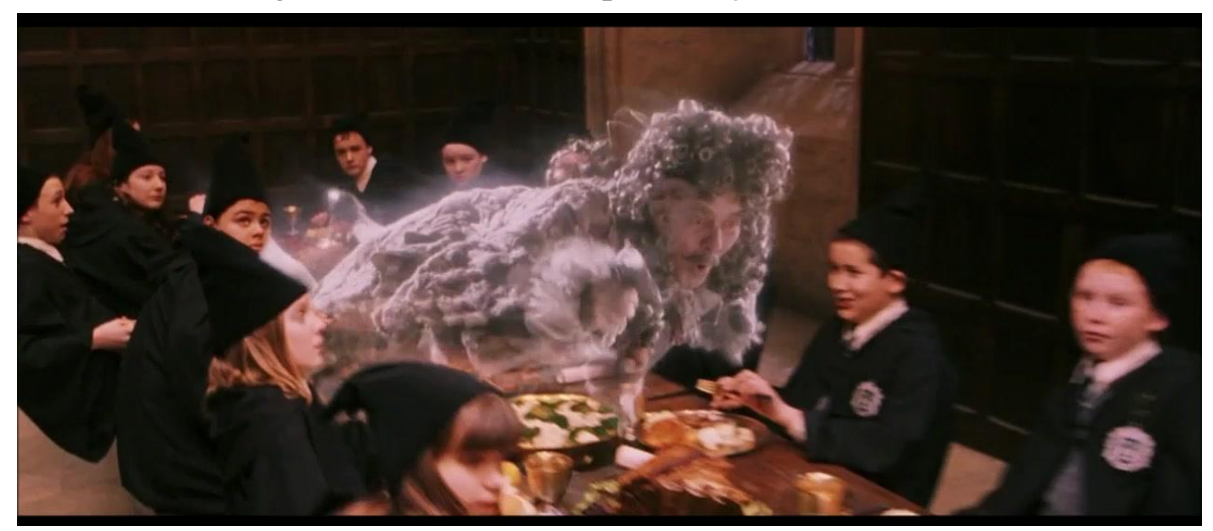

Fonte: Harry Potter e a Pedra filosofal (47’07'” à 47’32'').

Imagem 6 - Frame 3 da apresentação dos fantasmas

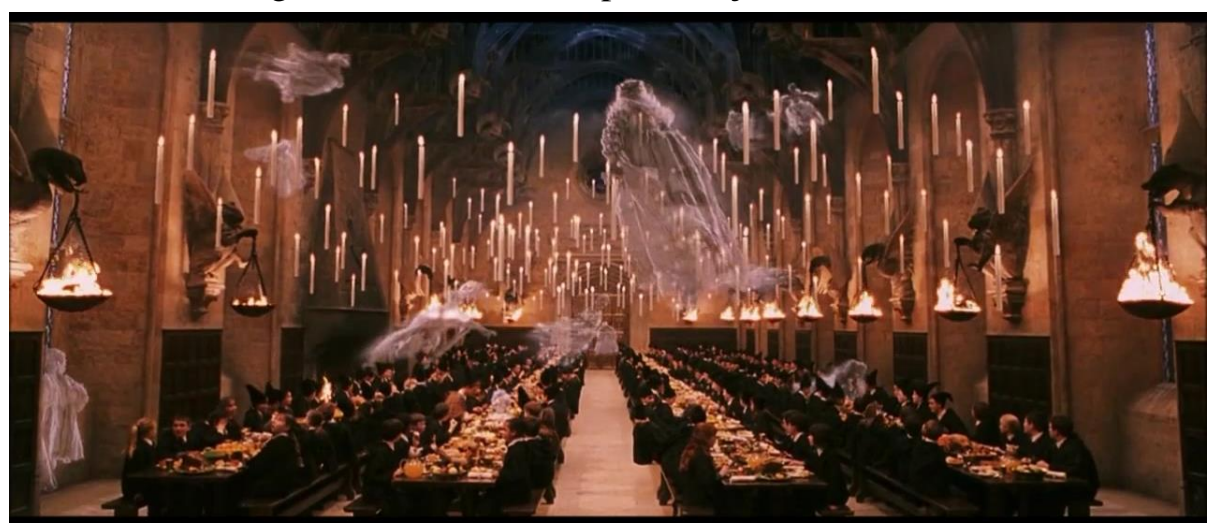

Fonte: Harry Potter e a Pedra filosofal (47’07'’ à 47’32'’).

A sequência sonora ${ }^{4}$ que acompanha a cena se utiliza da transição entre meios tons, em certos momentos destoantes entre si, o que modula o som como se este fosse uma extensão do conhecido barulho do qual fantasmas, em produções audiovisuais, se utilizam para assombrar determinado lugar ou pessoa. Mesmo que nenhum dos fantasmas nessa cena emita esse barulho para assustar os presentes (pois, aqui, é construída uma personalidade que não a de um fantasma ao estilo "fanfarrão" e que se diverte assombrando os vivos), o som está ali ao fundo, conforme eles surgem em diferentes pontos do recinto até que se mostre o plano panorâmico com todos.

Também em outros momentos do filme, que não foram trazidos especificamente nesse recorte, algumas sequências sonoras tendem a "materializar" as imagens na forma de som, seja remetendo a um som já existente, como é o caso da cena dos fantasmas, ou na tentativa de dar forma sonora a algo específico do mundo bruxo, como acontece com a apresentação do castelo acompanhada de uma sequência que remete ao mágico presente no ambiente (dos

\footnotetext{
${ }^{4}$ Disponível em: <https://youtu.be/1_IJ5P-iO6k>, aos 57’’. Acesso em: 3 ago. 2020.
} 
48'03' aos 48'55' do filme) e com a capa de invisibilidade (aos 88'02' e dos 90'10' aos 91'36'). De qualquer uma das formas, são possibilidades de efeitos emergentes da combinação corroborativa entre a trilha sonora e o âmbito imagético/narrativo.

\section{Efeitos reversos - segunda sequência}

A segunda sequência aqui apresentada advém de uma regularidade da trilha sonora cinematográfica (evidenciada no filme em referência especificamente, mas não impossível de ocorrer em outros materiais) em estabelecer um sentido não necessariamente idêntico ou que vai pelo mesmo caminho que o da imagem. Por "efeito reverso", entende-se que a modalização da sonoridade, individual e isoladamente, possibilita a emergência de um efeito que não seria o principal ou o primeiro que a imagem faria emergir, também individual e isoladamente. Sendo assim, colocados em conjunto, possibilitam efeitos distintos daqueles constatados no som corroborativo à imagem.

Uma das evidências dessa técnica é o uso da trilha sonora para atribuir um efeito cômico à imagem, não apenas no sentido de provocar riso, mas para expor situações tidas como absurdas fora do microcosmo do filme de forma que, na produção que se assiste, não remeta a esse terror que comumente teria, além de momentos em que há uma espécie de freio no enredo principal o qual dá espaço, por exemplo, à apresentação das relações subjetivas entre os personagens pelo meio situacional que se mostra.

Os frames a seguir são extraídos de uma dessas cenas cômicas, no sentido amplo supracitado. Trata-se do primeiro contato do protagonista com a mágica, que depois será sua nova realidade cotidiana, mas que, nesse momento, ainda é algo que espanta e desconhecido. Inicialmente, a comicidade é causada pelo sumiço do vidro que protege o ambiente de uma cobra no zoológico, causando a queda de um personagem para dentro do local: 
Imagem 7 - Frame 1 da visita ao zoológico

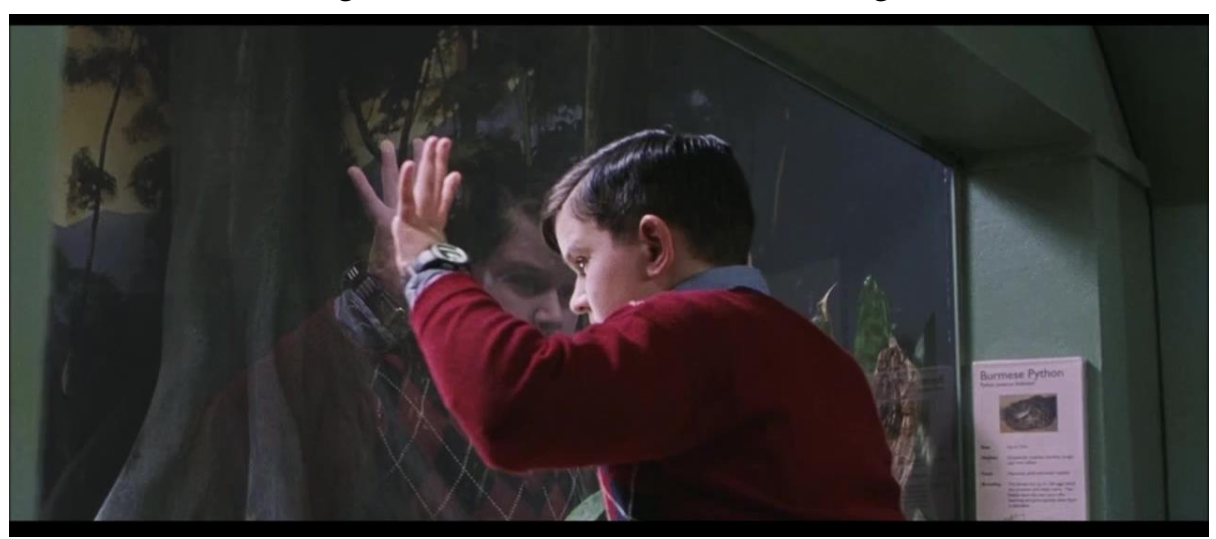

Fonte: Harry Potter e a Pedra filosofal (6'58', à 7'53', ).

Imagem 8 - Frame 2 da visita ao zoológico

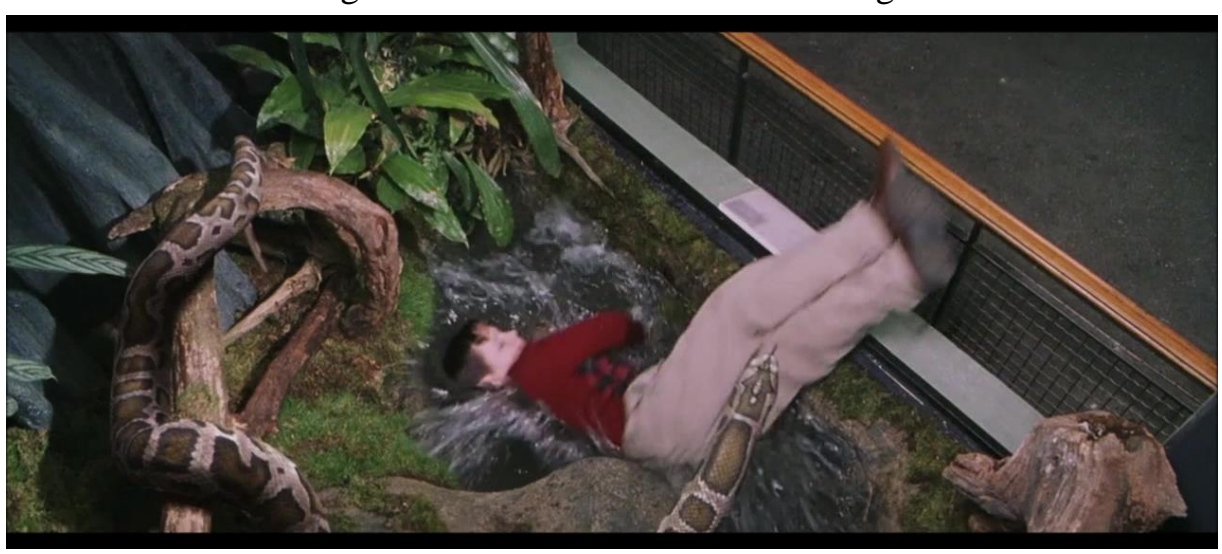

Fonte: Harry Potter e a Pedra filosofal (6'58', à 7'53', ).

Anterior a esse sumiço do vidro, ainda acontece a conversa entre o protagonista e o animal, também manifestação do microcosmo mágico do filme que em episódios posteriores se explica. Após a queda do outro personagem, se inicia uma sequência sonora ${ }^{5}$ de andamento rápido, com várias notas tocadas seguidamente e instrumentos que remetem ao som de violinos e sinos; todo esse conjunto oferece uma sonoridade animada, apressada, é o elemento normalizador que ameniza o espanto da cena ${ }^{6}$, que se segue com outro diálogo do protagonista com o animal e o pânico das outras pessoas com a fuga deste último do zoológico.

\footnotetext{
5 "Visit to the zoo". Disponível em: 〈https://youtu.be/hC0BFjkB85Q>, aos 25". Acesso em: 3 ago. 2020.

${ }^{6}$ Mais sobre elementos normalizadores que tranquilizam perturbações pode ser encontrado em: COURTINE, Jean. Jacques. O corpo anormal: história e antropologia culturais da deformidade. In: CORBIN, Alain; COURTINE, Jean. Jacques; VIGARELLO, Georges. (org.). História do corpo. Petrópolis: Vozes, 2008, p. 253340 .
} 
Imagem 9 - Frame 3 da visita ao zoológico

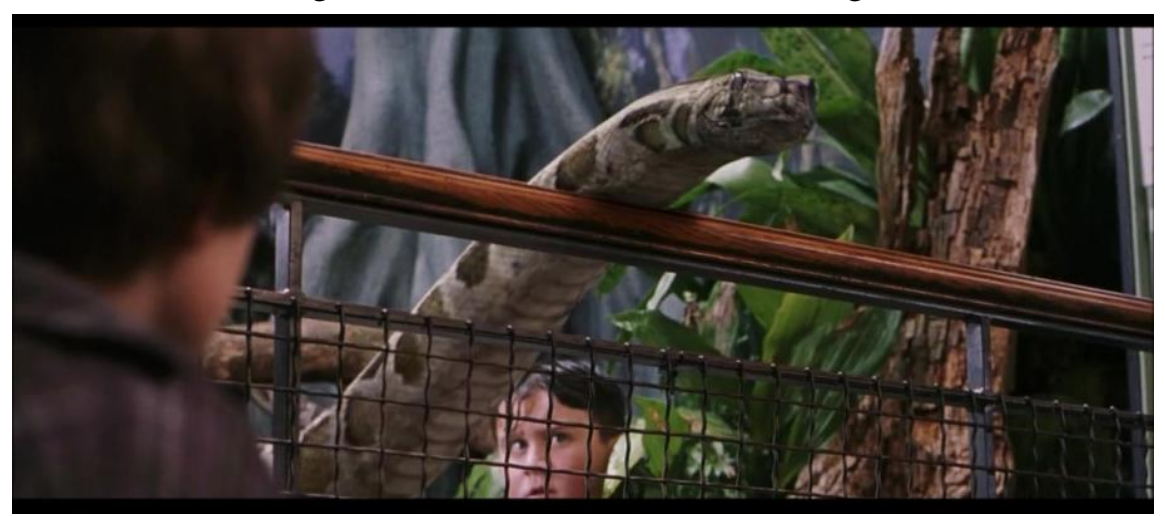

Fonte: Harry Potter e a Pedra filosofal (6'58'” à 7'53').

Imagem 10 - Frame 4 da visita ao zoológico

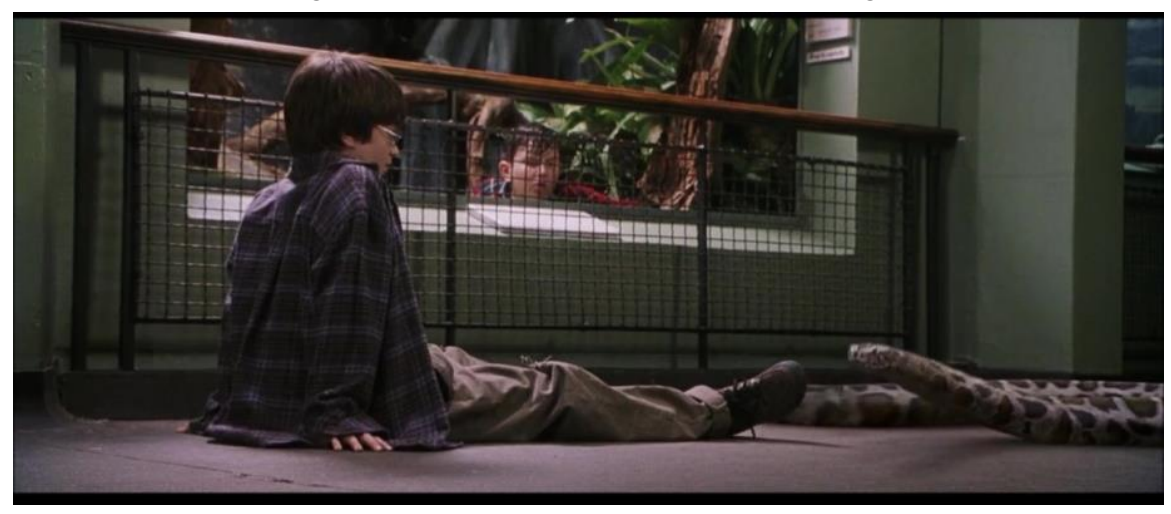

Fonte: Harry Potter e a Pedra filosofal (6'58' à 7'53'').

De maneira semelhante, outra ocorrência se situa já em momento avançado da narrativa, no qual o trio principal se depara com um ovo de dragão, que está sob cuidados do personagem da Figura 3, bastante excêntrico no universo do filme e que despende cuidados fraternais ao objeto peculiar. Toda a cena, desde o momento em que as crianças veem o ovo até o que este se choca e se quebra, é acompanhada também de uma sequência sonora animada, leve, a qual, semelhante àquela da cena do zoológico, é executada concomitantemente a uma situação que, por si só, teria outro tom e outros efeitos de sentido primeiros.

Nesse caso, os enquadramentos e foco se alternam entre as expressões dos personagens que, conforme suas reações diante do objeto desconhecido e, aparentemente, perigoso, indicam um tom para o cenário situacional ali representado. Entretanto, o efeito reverso se dá a partir do funcionamento da sequência sonora inusitada e da expressão do personagem guardião do objeto, o qual, ao contrário dos outros três, transmite uma sensação 
de expectativa para com o que está por surgir dali. O espectador, então, é pego nesse entrave entre a expectativa e a antecipação de que algo assustador está para acontecer.

Imagem 11 - Frame 1 do nascimento do dragão

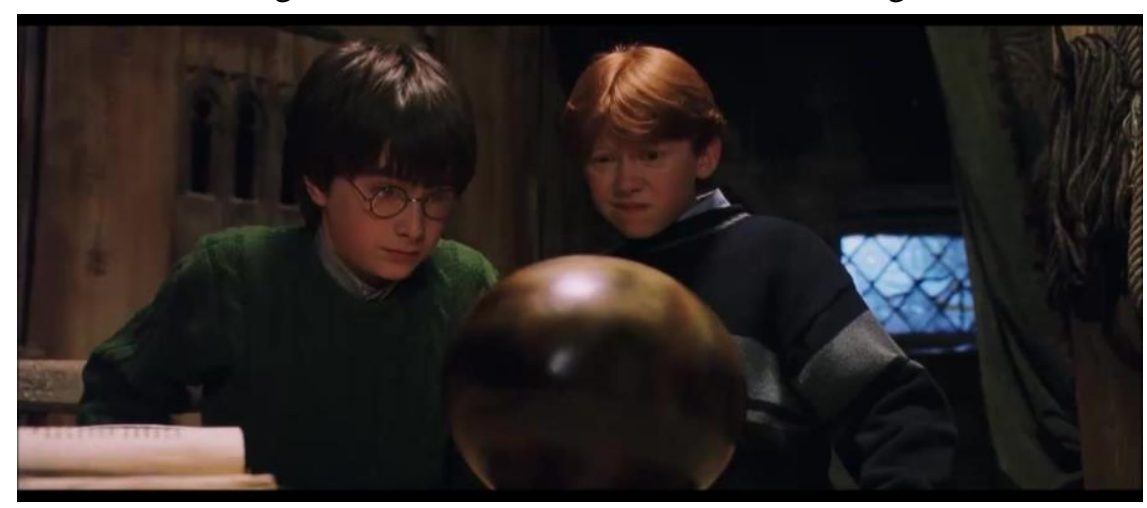

Fonte: Harry Potter e a Pedra filosofal (100'19'” à 101'17'”).

Imagem 12 - Frame 2 do nascimento do dragão

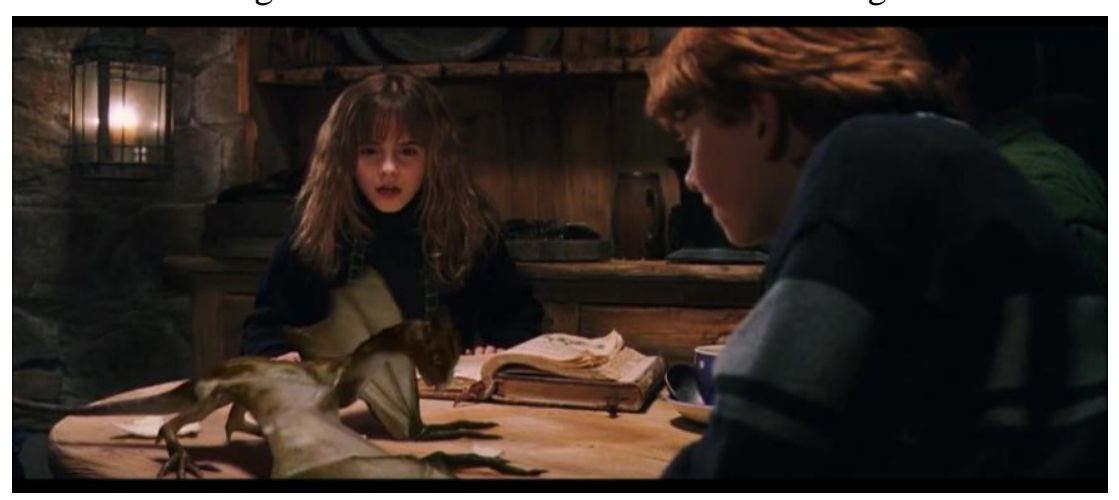

Fonte: Harry Potter e a Pedra filosofal (100'19'” à 101'17'”).

Nesse sentido, a partir da identificação e análise de tais sequências aqui expostas, mas não apenas elas, pode-se compreender a atuação do canal sonoro de informação na composição íntegra de uma cena e, posteriormente, de uma produção cinematográfica. Quando manuseados e colocados de determinada forma e não outra, os elementos da cinematografia configuram a rede de dispositivos que perpassam esse ambiente fílmico, de modo que não existe um certo ou errado no que diz respeito aos efeitos de sentido e lugares vazios de sujeito estabelecidos, mas sim um leque de possibilidades atribuídas ao que constitui os dispositivos ali presentes. 


\section{Considerações finais - um lugar a ser ocupado}

Com essa proposta de um estudo discursivo da cinematografia sonora, procurou-se relações de saber entre as ditas partes, considerando o conceito de cinema como uma impressão da realidade e como um local no qual os sujeitos diversos podem se colocar, bem como os processos de identificação que daí emergem.

Ao perpassar a conceituação de dispositivo conforme os estudos foucaultianos, percebe-se a participação desse agente na produção de subjetividades na forma da trilha sonora, a qual, para muito além de um componente adicional, pode ser encarada como constituinte essencial na rede que forma o todo representado, na tela, na forma de um microcosmo de certa produção. Uma vez que esse microcosmo se constitua como um sistema que explica ou coloca em discussão os problemas humanos, as relações de saber e poder ali identificadas contribuem à criação de sujeitos "livres", para se usar a determinação de Foucault, os quais assumem sua identidade mediante o compartilhamento de emoções e situações para com a representação fílmica, seja no sentido de agregá-las ou rechaçá-las.

Também compartilhando a existência e singularidade do dispositivo audiovisual, foi possível delimitar alguns caminhos do processo de construção de sentido no qual os sujeitos se envolvem, seja na produção ou na recepção do filme de maneira geral. Tanto a trilha sonora que corrobora a cena quanto a que produz efeitos reversos ou as sequências leitmotiv devem ser moduladas, junto ao trabalho de câmera, para que, de uma maneira ou de outra, aconteça a perda de vigilância do espectador e, consequentemente, a forma como a situação foi proposta se torne crível e a conhecida "magia do cinema", oferecendo os índices de realidade necessários a uma impressão do real, produza seus efeitos de saber.

O percurso aqui feito procurou expor minuciosidades dessa sonoridade de um cinema "bruxo", por meio das sequências musicais presentes no todo do filme que, pelo aporte teórico foucaultiano, produzem seus efeitos e os lugares possíveis de subjetivação. Não menos importante também há o destaque ao domínio de memória que permeia a produção de Harry Potter e remete ao mundo bruxo e mágico; por esse viés discursivo é possível se recuperar a memória social relacionada à magia, bem como se percebe a retomada de um discurso e saber social a respeito do fantástico no audiovisual, ricamente incrementado com elementos sonoros que possibilitam a criação de singularidades para esse domínio.

Enfim, pelos movimentos sonoros e visuais que se imprimem em um produto cinematográfico, analisado discursivamente, constata-se sua atuação em diversos sentidos humanos de forma que, artisticamente, oferece esse lugar de identificação. Conforme Gros 
constata, a cultura seria o lugar de onde se tira modelos de vida, esse seria seu papel, e ainda sintetiza que "Somos morais por nos sentir convocados a agir, e é a imaginação das narrativas que [nos] sustenta" (2018, p. 209); e é por esse compartilhamento de sentimentos para com o artístico pluralmente sensitivo que os sujeitos sociais se constituem, minimamente, capazes de serem atuantes de maneira humanizada para com seus semelhantes.

\section{Referências}

AGAMBEN, Giorgio. O que é um dispositivo? Outra travessia, n. 5, p. 9-16, 2005. Disponível em: <https://periodicos.ufsc.br/index.php/Outra/article/view/12576/11743>. Acesso em: 13 jul. 2020. DOI: https://doi.org/10.11606/issn.2238-7714.no.2012.55404.

ALVEZ, Bernardo Marquez. Trilha Sonora: o cinema e seus sons. Novos olhares, v. 1, n. 2, p. 90-95, $30 \quad$ dez. 2012. Disponível em: <https://www.revistas.usp.br/novosolhares/article/view/55404/59008>. Acesso em: 13 jul. 2020. DOI: https://doi.org/10.11606/issn.2238-7714.no.2012.55404

ANDREW, James. Dudley. As principais teorias do cinema. Tradução Teresa Ottoni. Rio de Janeiro: Zahar, 2002.

AUMONT, Jacques. et al. A estética do filme. Tradução Marina Appenzeller. 9. ed. São Paulo: Papirus, 2012.

CARVALHO, Pedro. Henrique Varoni; SARGENTINI, Vanice Maria Oliveira. Dispositivo, discurso e produção de subjetividades. In: FERNANDES JÚNIOR, Antônio; SOUSA, Kátia Menezes (org.). Dispositivos de poder em Foucault: práticas e discursos da atualidade. 2. ed. Catalão: Letras do Cerrado, 2017, p. 25-36.

FOUCAULT, Michel. História da sexualidade I: A vontade de saber. Tradução Maria Thereza da Costa Albuquerque e J. A. Guilhon Albuquerque. Rio de Janeiro: Edições Graal, 1988, p. 75-123.

FOUCAULT, Michel. A arqueologia do saber. Tradução Luiz Felipe Neves. 7. ed. Rio de Janeiro: Forense Universitária, 2008.

FOUCAULT, Michel. Ditos e escritos VI: Repensar a política. Tradução Ana Lúcia Paranhos Pessoa. Rio de Janeiro: Forense Universitária, 2010.

FOUCAULT, Michel. Microfísica do poder. Organização, introdução e revisão técnica de Roberto Machado. 27. ed. São Paulo: Graal, 2013.

GROS, Frédéric. Desobedecer. Tradução Célia Euvaldo. São Paulo: Ubu Editora, 2018.

HARRY POTTER E A PEDRA FILOSOFAL. Direção de Chris Columbus. Produção de David Heyman. Roteiro de J. K. Rowling e Steve Kloves. Interpretação de Daniel Radcliffe, 
Rupert Grint, Emma Watson e Alan Rickman. [S. I.]: Warner Bros. Pictures, 2001. 1 DVD (152 min), trilíngue: inglês, espanhol e português. $4 \times 3$ fullscreen. Edição especial - box.

MILANEZ, Nilton; BARROS-CAIRO, Cecília; BRAZ, Analyz Pessoa. Dispositivo audiovisual: percursos de uma construção teórico-analítica. In: FERNANDES JÚNIOR, Antônio; SOUSA, Kátia Menezes (org.). Dispositivos de poder em Foucault: práticas e discursos da atualidade. 2. ed. Catalão: Letras do Cerrado, 2017, p. 223-233.

NAVARRO, Pedro. Acontecimento discursivo e efeitos de poder sobre o sujeito idoso. In: BUTURI JÚNIOR, Atílio; SEVERO, Cristiane Groski (org.). Foucault e as linguagens. Campinas: Pontes Editores, 2018, p. 267-296.

Recebido em: 5 de agosto de 2020

Aceito em: 30 de outubro de 2020 